\section{Erratum}

http://dx.doi.org/10.11646/zootaxa.3796.3.11

http://zoobank.org/urn:lsid:zoobank.org:pub:20A8BCDA-2B7D-4226-9BC7-75ACA5EAB648

\title{
JHABAR MAL, RAJENDRA NAGAR \& R. SWAMINATHAN (2014) Record of Natula matsuurai Sugimoto (Orthoptera: Gryllidae: Trigonidiinae) and other sword-tailed crickets from India. Zootaxa, 3760(3): 458-462.
}

Please find the following plates as part of the article:
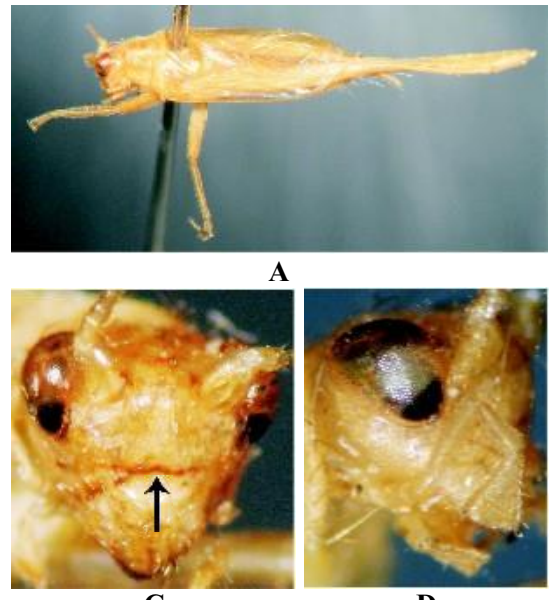

D
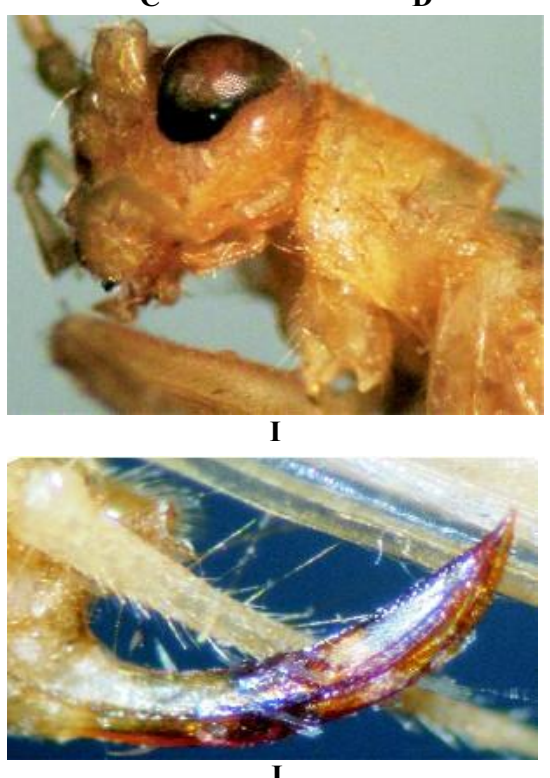

$\mathbf{J}$

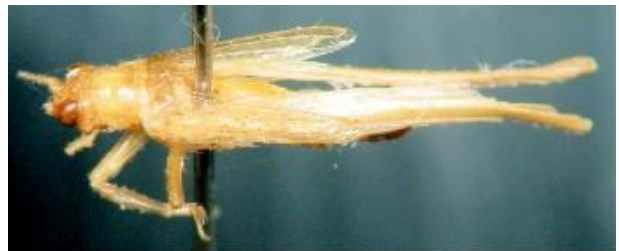

B

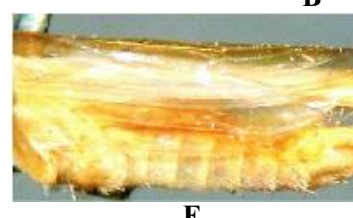

$\mathbf{E}$
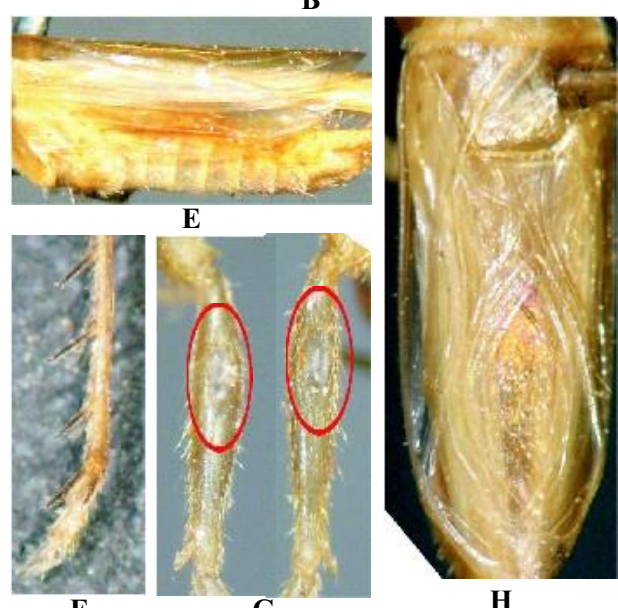

H

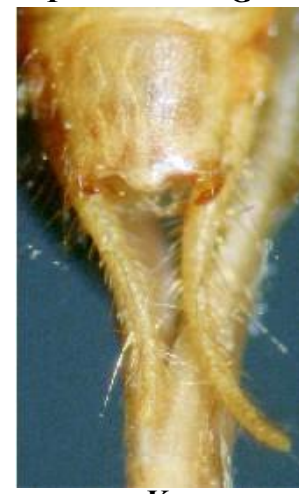

K

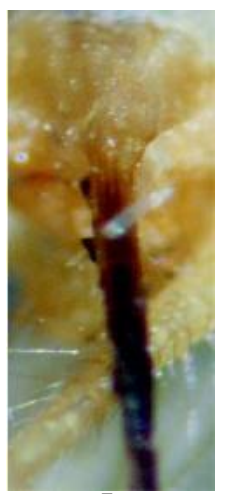

$\mathbf{L}$

PLATE IA. Natula Gorochov, 1987. (A-L), Natula matsuurai (Sugimoto, 2001) : A, Male; B, Female; C, Face with a transverse dark strip near epistomal suture; D, Fifth joint of maxillary palpi hatchet shaped; E, Lateral field of tegmina deeper than lateral lobe of pronotum; F, Hind tibia with 3 pairs of dorsal spines on both sides but largest inner apical spurs as long as or half of basitarsus; G, Fore tibia with oval shaped outer and inner tympanum; H, Harp vein only one, Mirror area occupying half dorsal surface, not divided with a small concentric inner veinlet; I, Pronotum with roundly convex anterior margin; J, Female ovipositor strongly upcurved, half as long as hind femur, three fifth area from base widened and bumpy, with a dorsal groove, cerci as long as ovipositor; K, Male sub-genital plate longer than wide, hind margin narrowly truncated with a small projected median lobe, two styli present; L, Female sub-genital plate roundly triangular. 

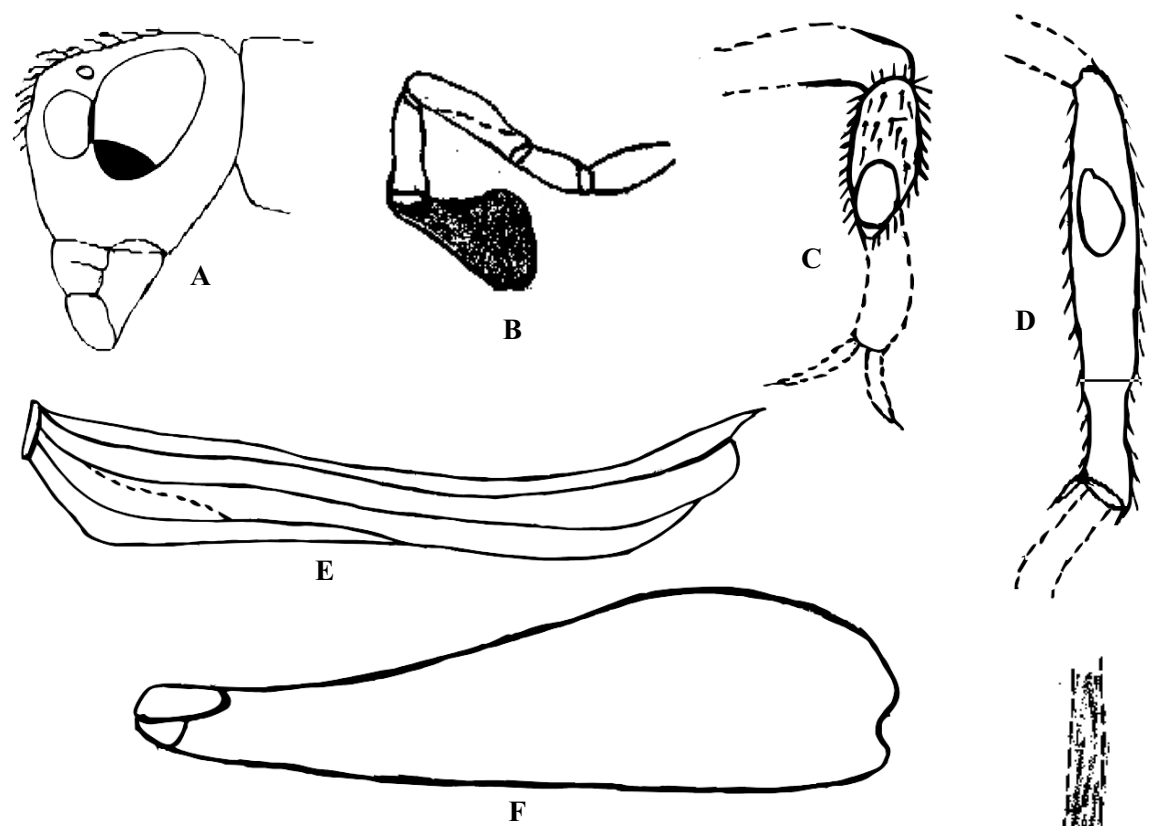

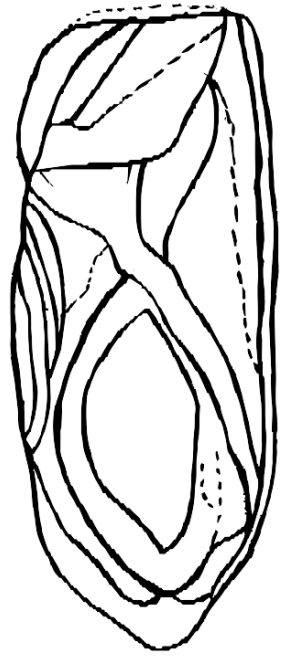

G
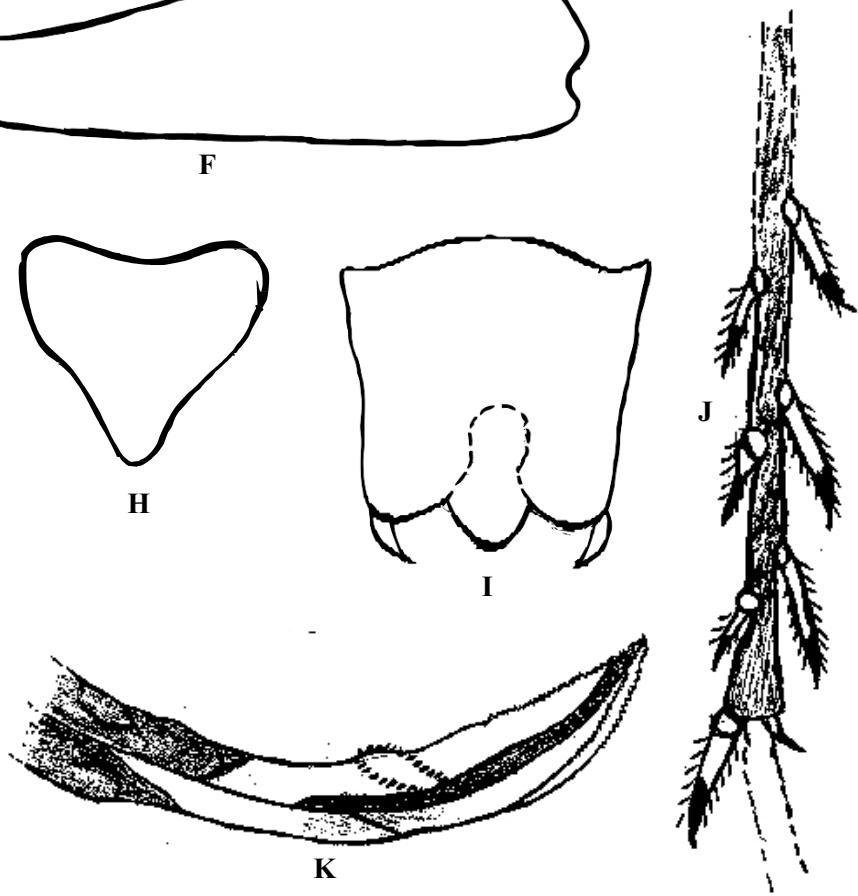

PLATE IB. Natula Gorochov, 1987. (A-K), Natula matsuurai (Sugimoto, 2001) : A, Head; B, Maxillary palpi; C, Second tarsal segment; D, Tympanum on fore tibia; E, Forewing lateral view showing longitudinal veins; F, Hind femur without stripe; G, Male Forewing mirror longer than wide; H, Female sub-genital plate triangular; I, Male sub-genital plate longer than wide, hind margin with a small projected median lobe; J, Hind tibial spines (3 pairs) on both sides; K, Ovipositor upcurved with a dorsal groove. 


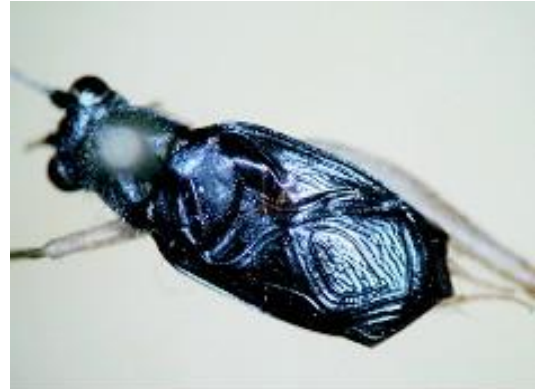

A

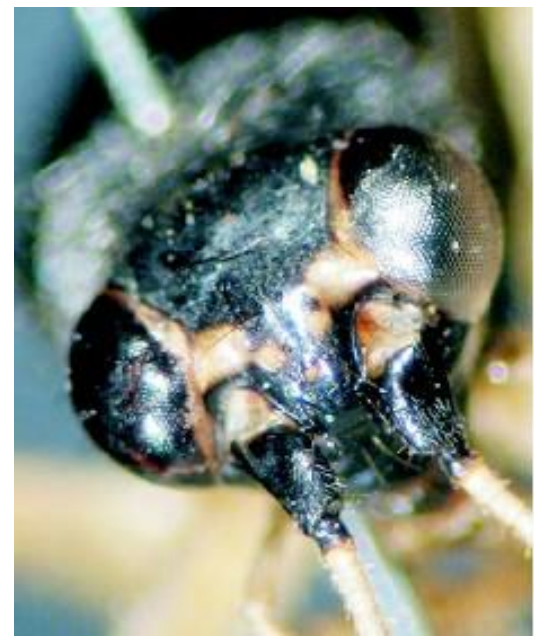

C

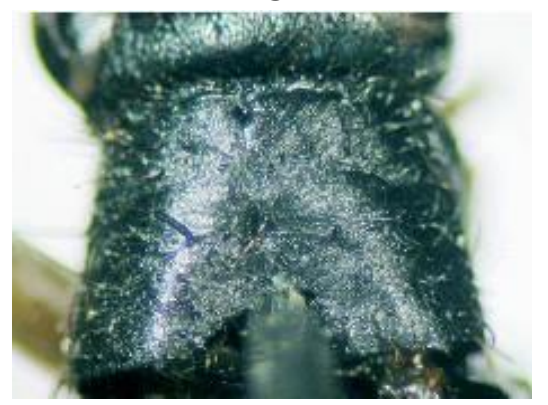

D

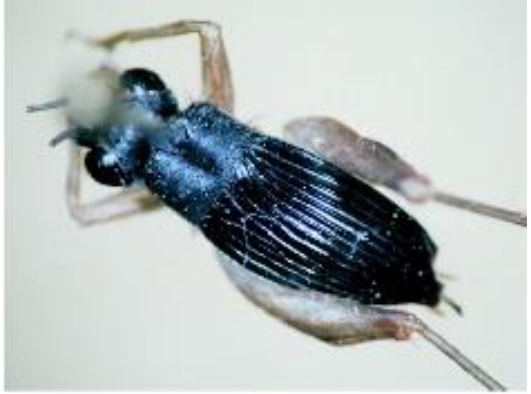

B

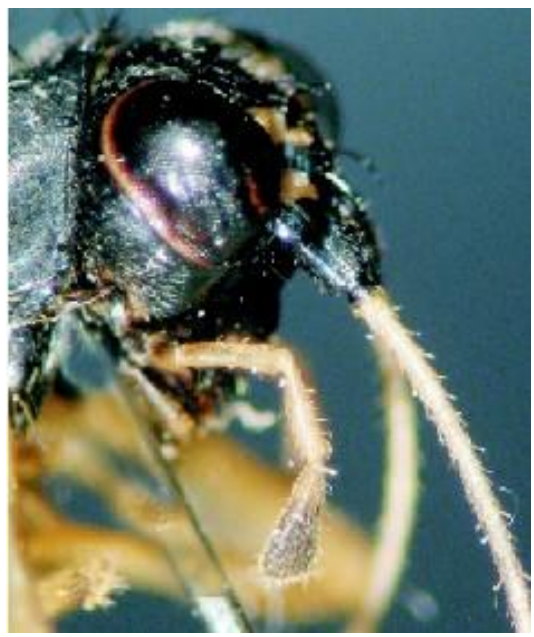

E

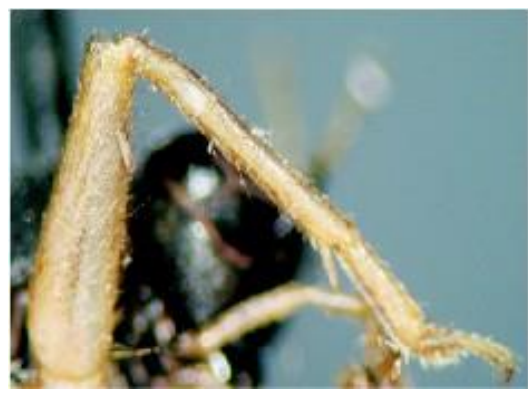

F

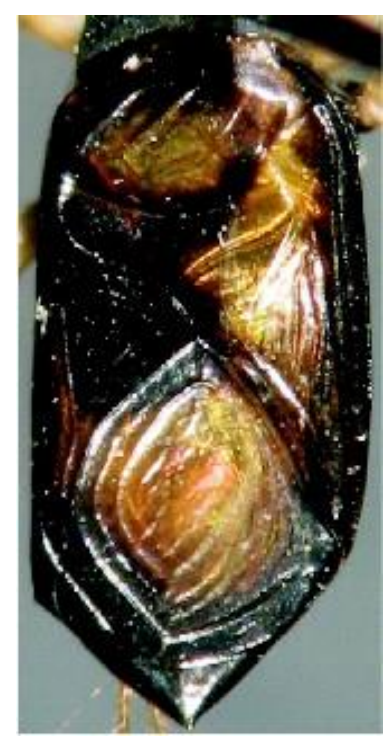

G

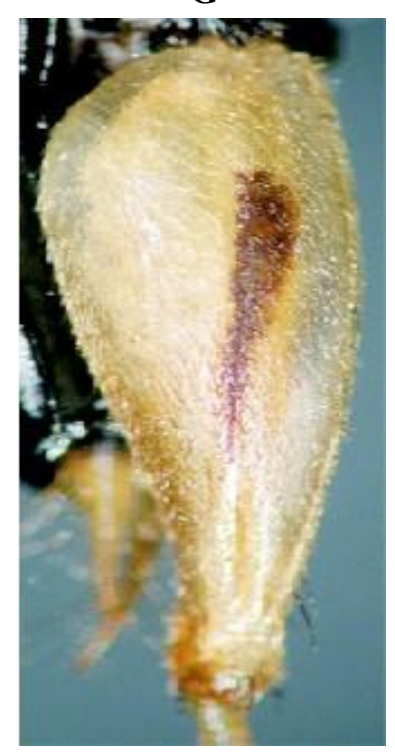

H
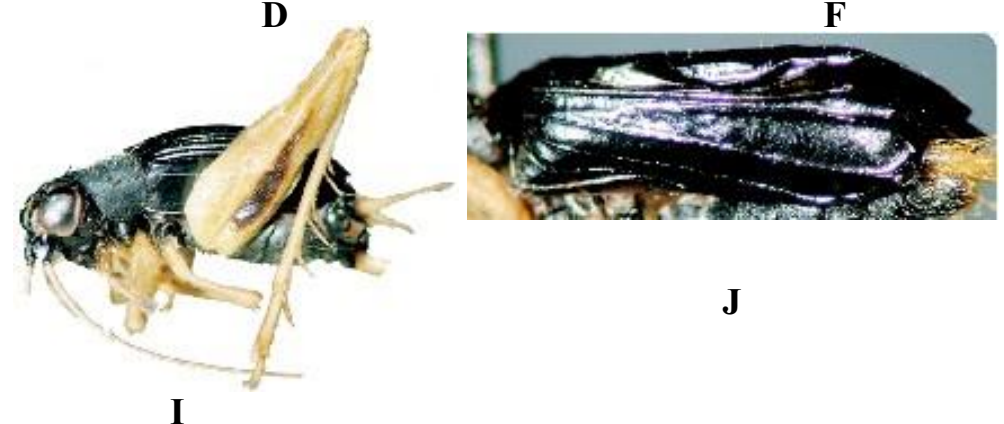

J

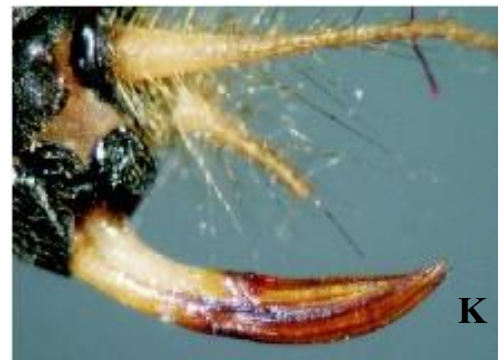

PLATE IIA. Paratrigonidium Brunner, 1893. (A-K), Paratrigonidium nitidum Brunner, 1893 : A-B, Male and female black, shining;the male with membranous elytra, while female elytra corneous, convex with plain, longitudinal veins. Vertex flattened and sloping; C, Head wide and black; antenae yellow with first joint black; D, Pronotum black, pubescent; E, Palpi long, yellowish, fifth joint of maxillary palpi long, feebly widening at apex; F, Tympanum external; G, Male elytra membranous; $\mathrm{H}$, The hind femurwith a feeble brownish band/stripe; I, Legs yellowish; J, Lateral field of tegmina in male blackish, presenting 3 parallel veins andthe fourth incomplete; K, The female ovipositor fulvous at base, darkened in the middle, cerci long. 


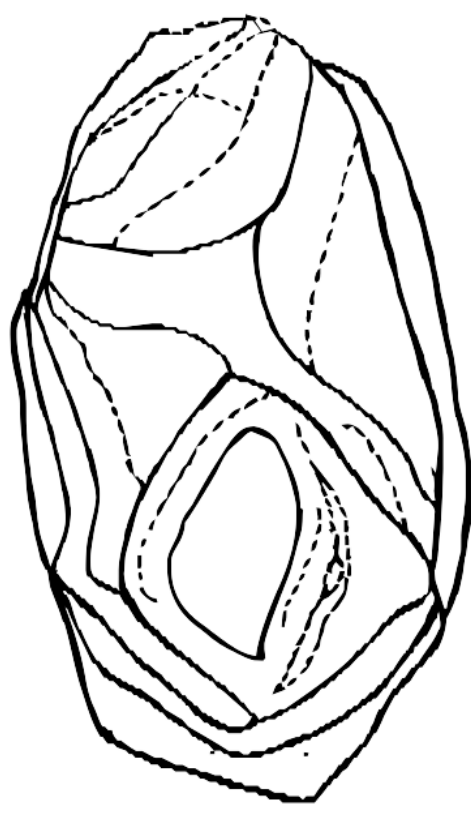

A
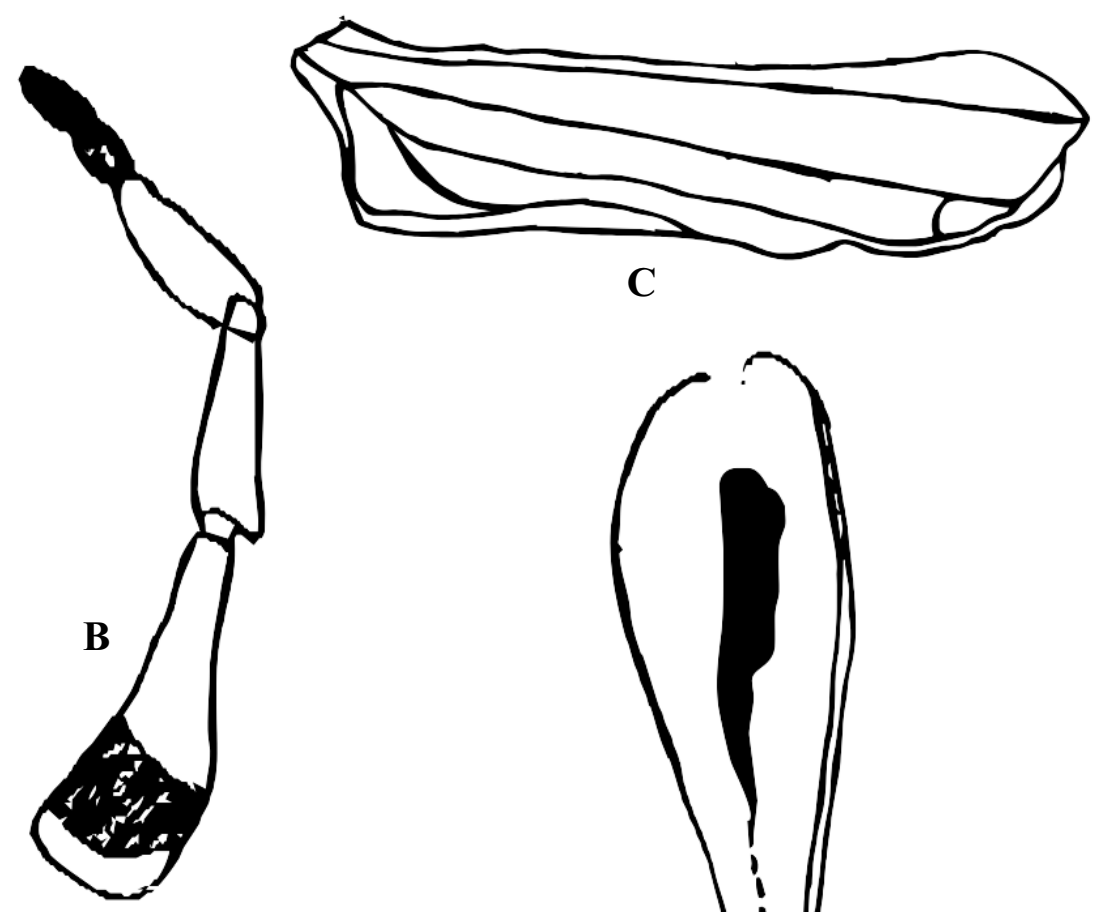

C
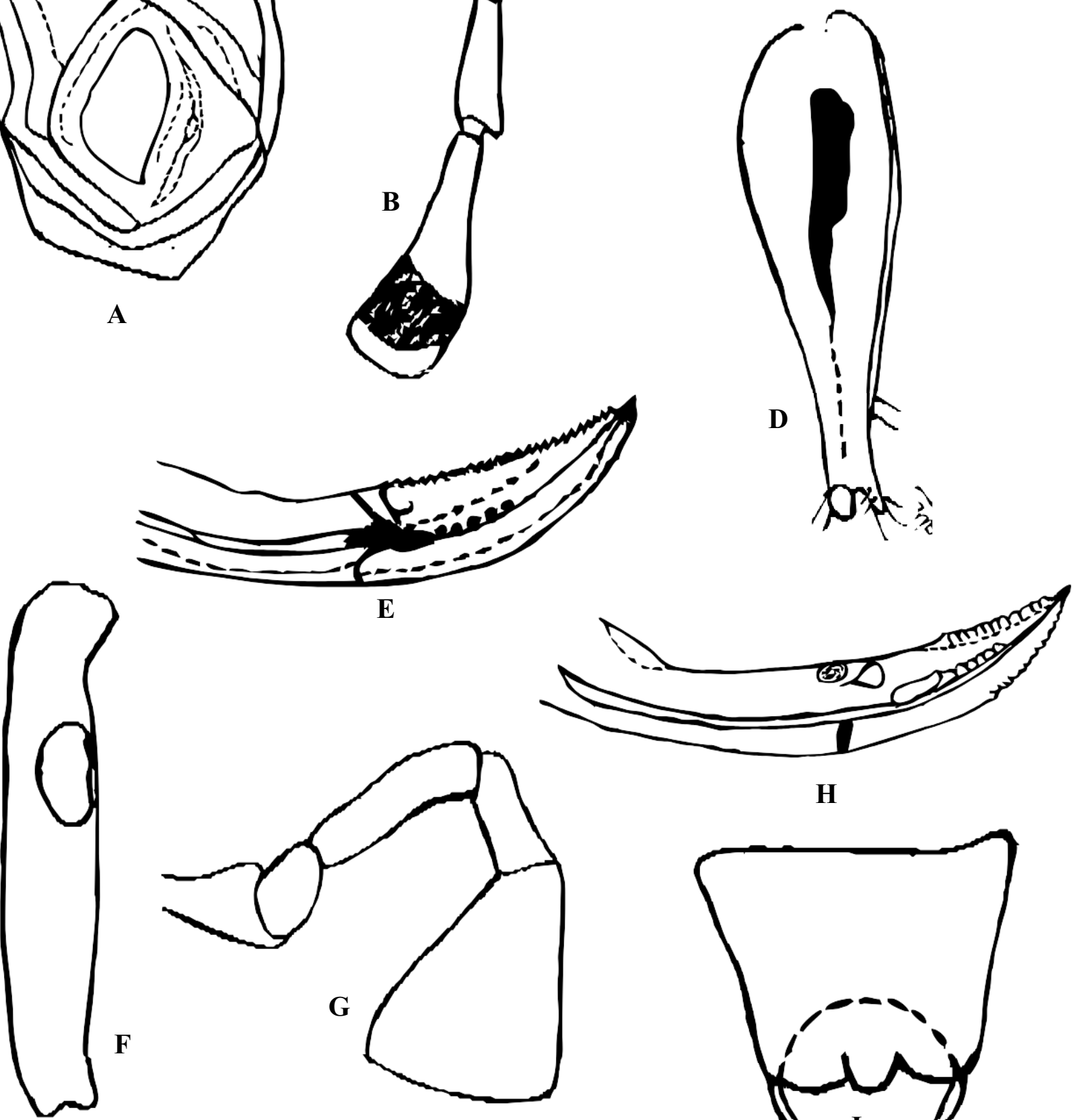

$\mathbf{H}$

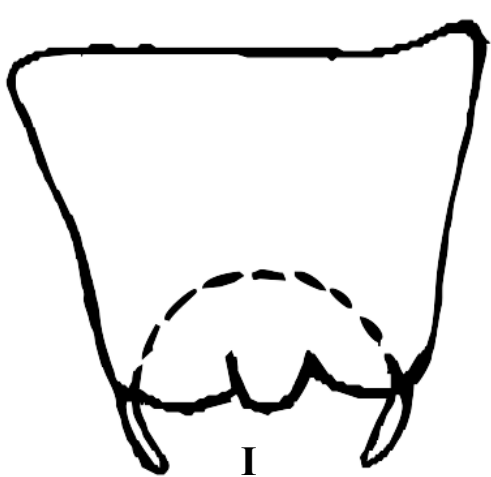

PLATE IIB. Paratrigonidium Brunner, 1893. (A-E), Paratrigonidium nitidum Brunner, 1893 : A, Male elytra membranous \& harpvein only one; B, Palpi long, yellowish, fifth joint of maxillary palpi long, feebly widening at apex; C, Lateral field of tegmina inmale blackish, presenting 3 parallel veins and the fourth incomplete; D, The hind femur with a feeble brownish band/stripe; E, The female ovipositor fulvous at base, darkened in the middle. Trigonidium Rambur, 1839. (F-I), Trigonidium humbertianum (Saussure, 1878): F, Anterior tibiae with tympanum on both sides; G, Fifth joint of maxillary palpi large and triangular; H, Female ovipositor curved, compressed, acute at apex; I, Male sub-genital plate feebly notched at apex. 


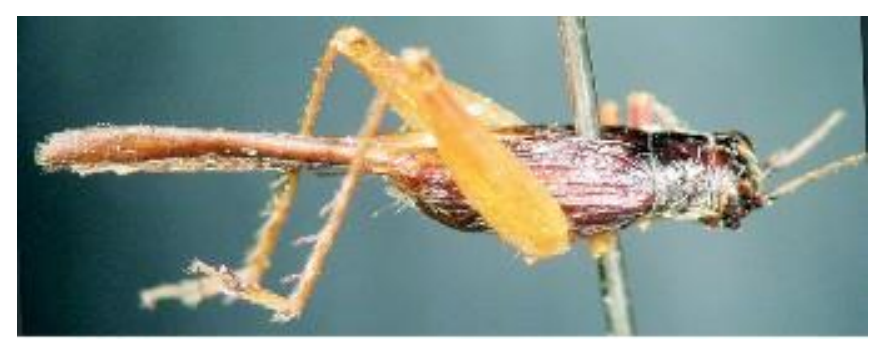

$\mathbf{A}$

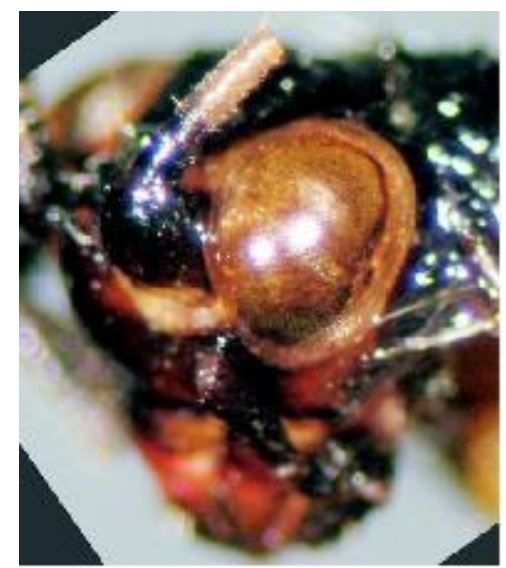

C

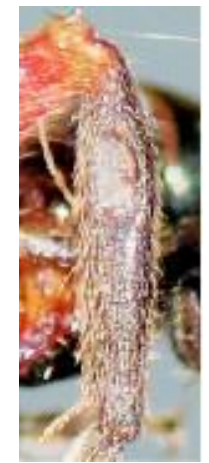

F

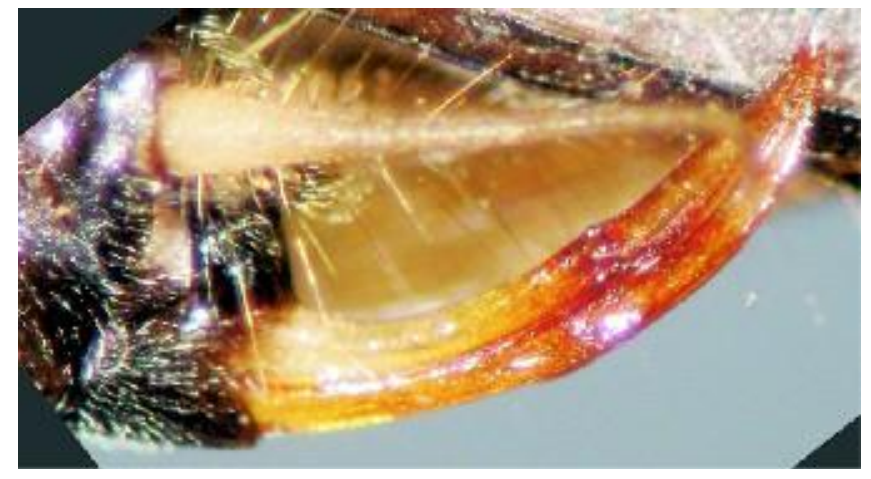

G

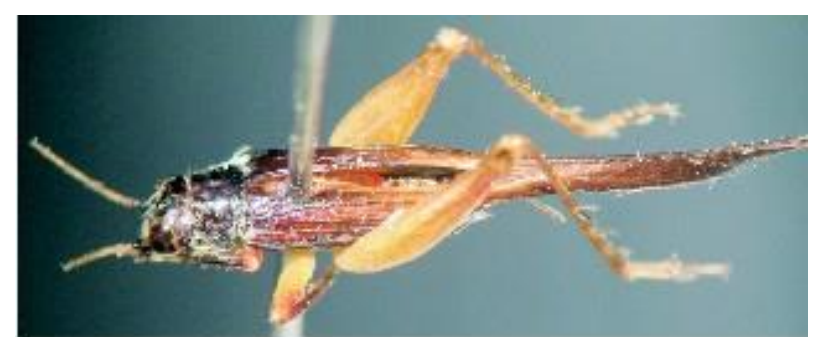

B

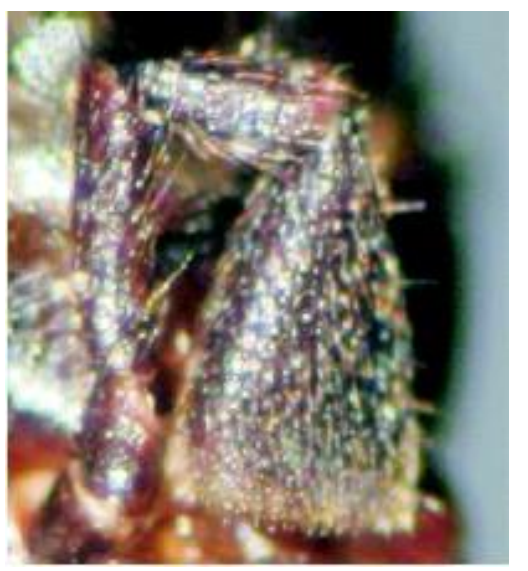

D

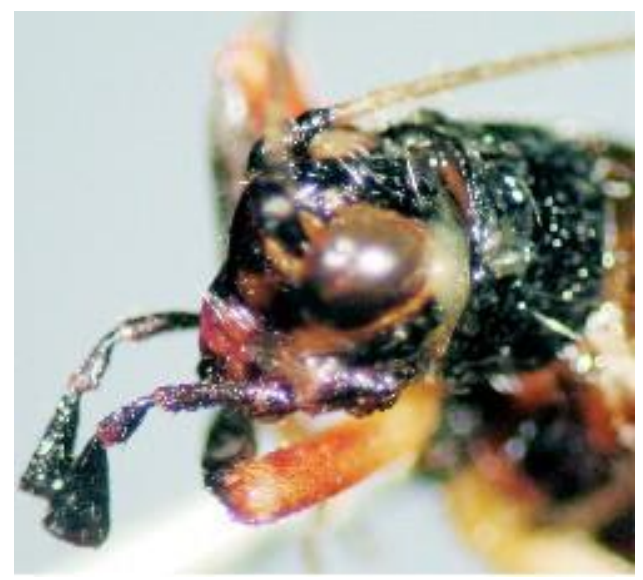

E

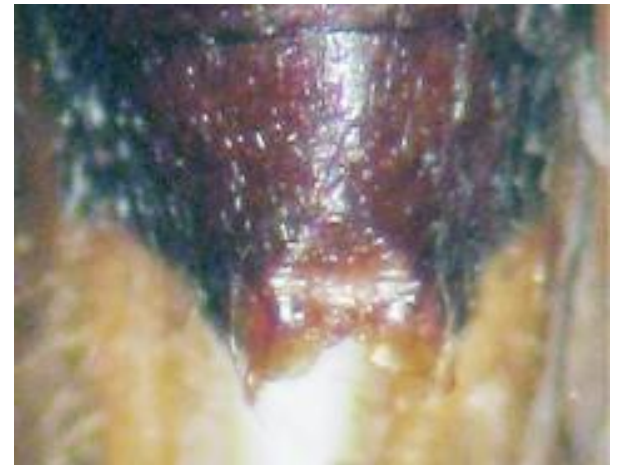

H

PLATE III. Trigonidium Rambur, 1839. (A-H), Trigonidium humbertianum (Saussure, 1878) : A, Male; B, Female; C, Eyesrounded protruding; D-E, Fifth joint of maxillary palpi large and triangular; F, Anterior tibiae with tympanum on both sides; G, Female ovipositor curved, compressed, acute at apex; H, Male sub-genital plate feebly notched at apex. 


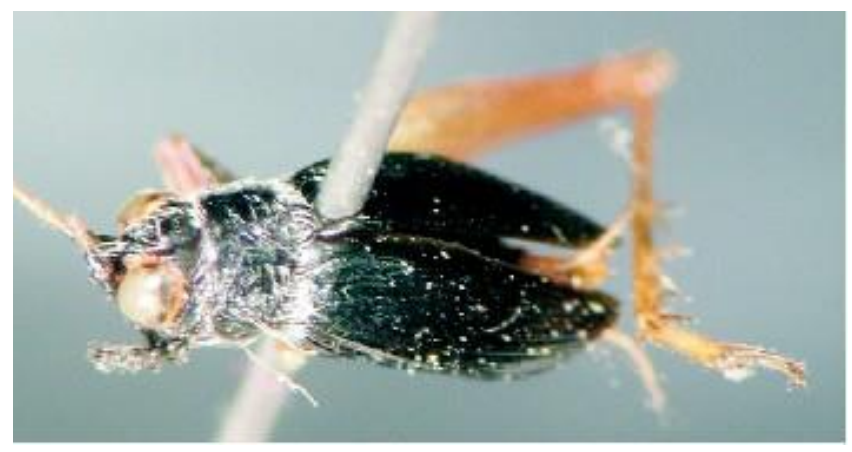

A

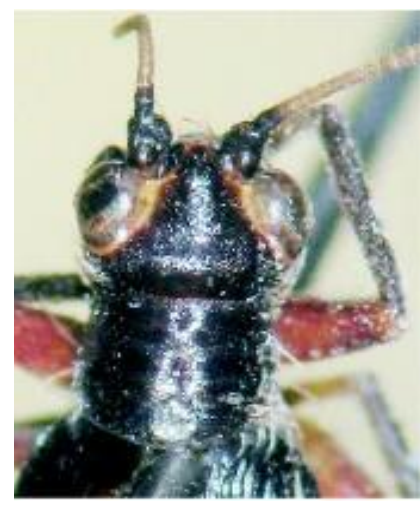

B
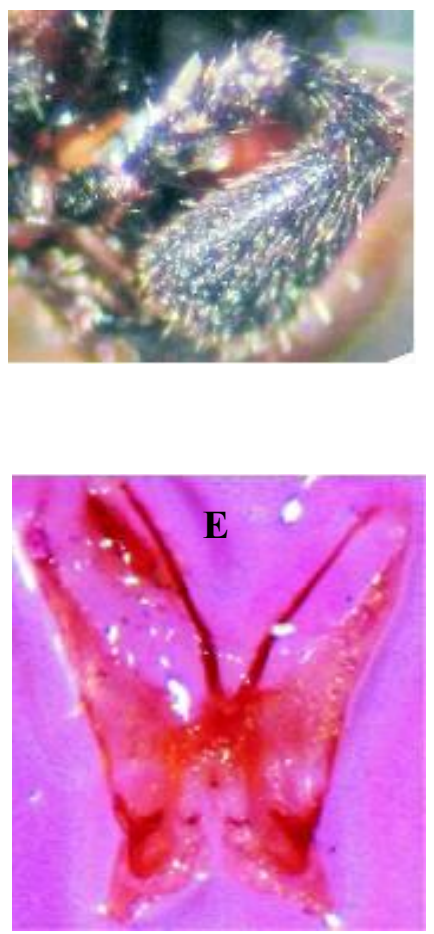

$\mathbf{F}$

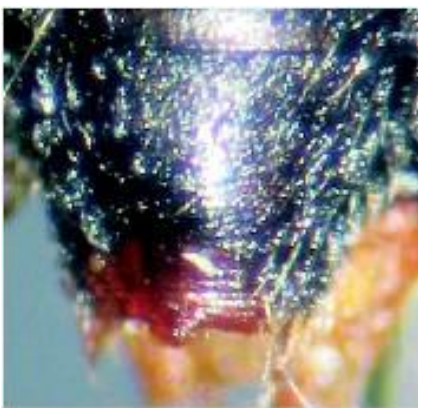

C

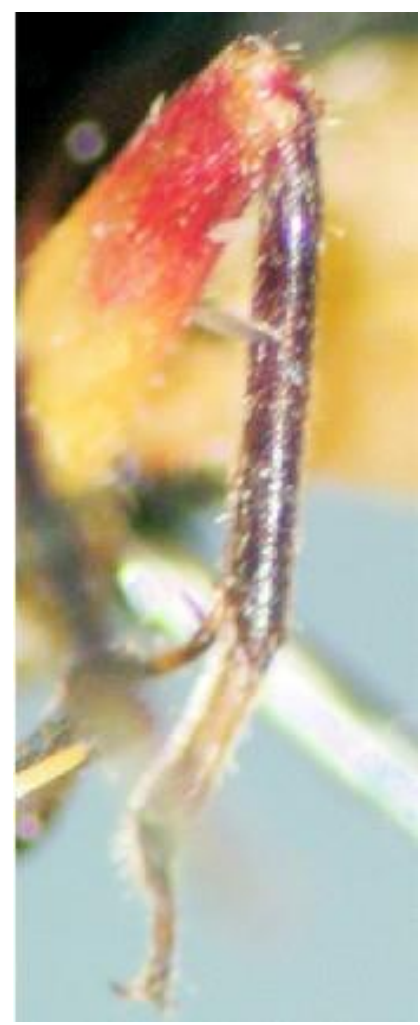

D

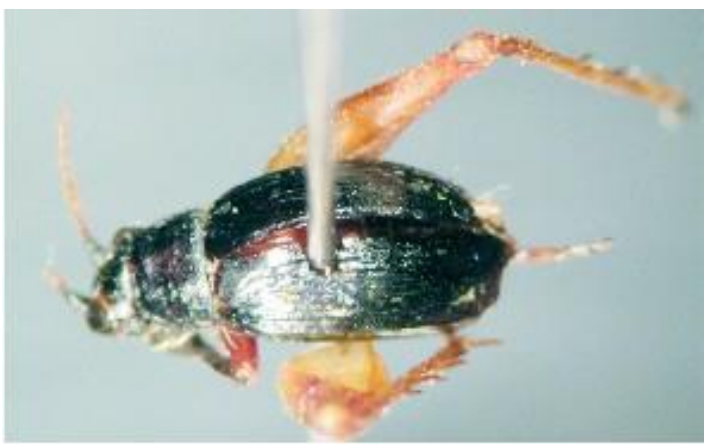

G

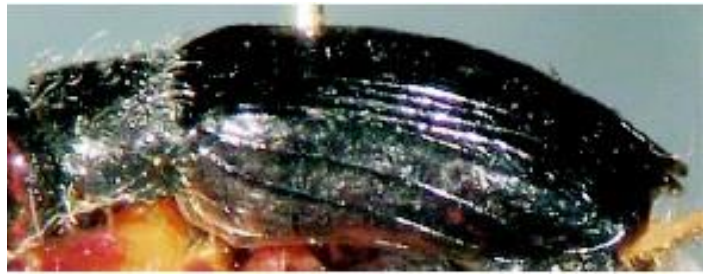

$\mathbf{H}$
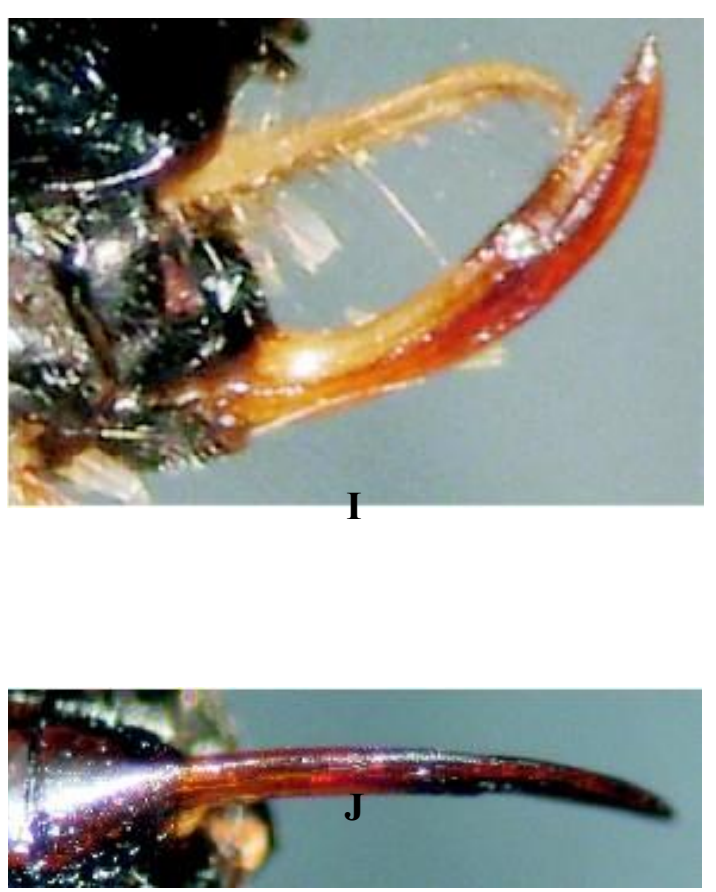

PLATE IVA. Metioche Stal, 1877. (A-J), Metioche japonica (Ichikawa, 2001) : A, Male; B, Inner margin of eyes more brightlyrimmed; C, Male sub-genital plate; D, Fore tibiae without tympanum on both sides; E, Shape of last segment of maxillary palpi-securiform; F, Male genitalia; G, Female; H, Tegmina convex; I, Female ovipositor upturned, shaped; apex sharp with teeth on; J, subgenital plate triangular. 


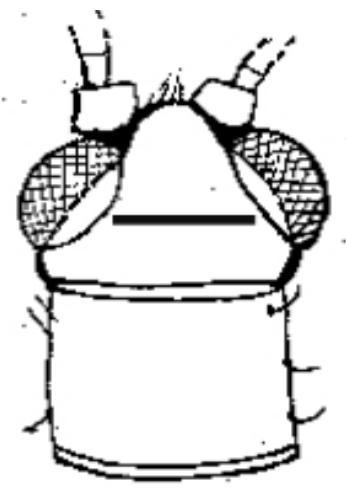

A

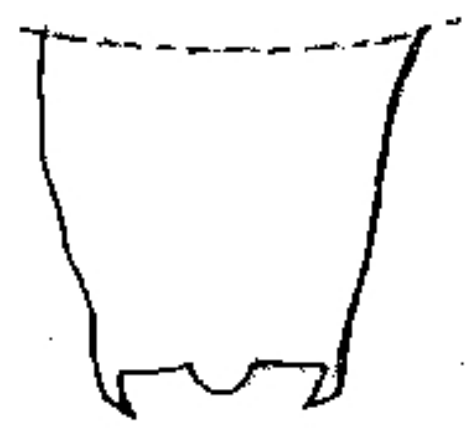

E

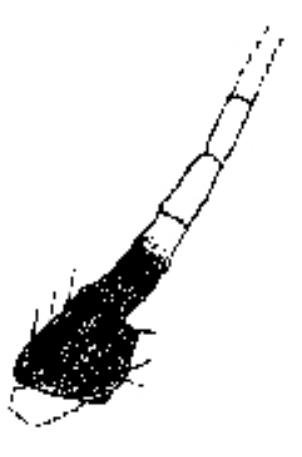

B

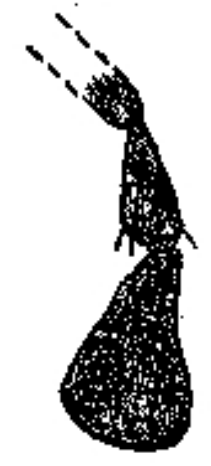

C

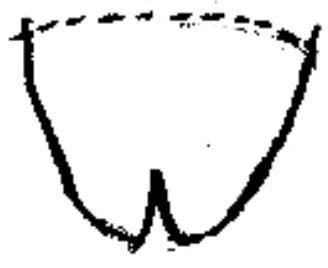

D

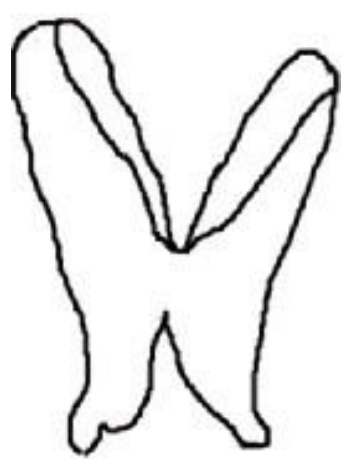

F

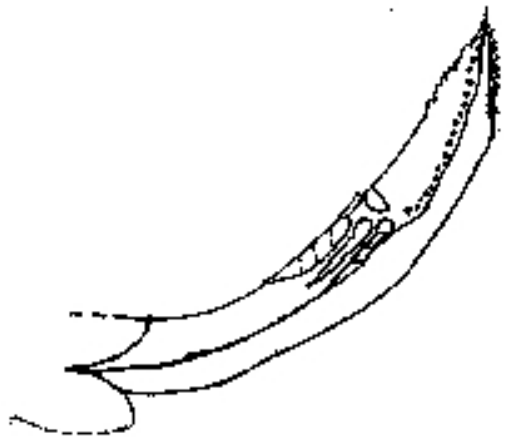

G

PLATE IVB. Metioche Stal, 1877. (A-G), Metioche japonica (Ichikawa, 2001): A, Eyes rounded, large and widely separated; B,Antennae: Scape and pedicel dark black, flagellum light in colour; C, Shape of last segment of maxillary palpi-securiform; D, Female sub-genital plate triangular; E, Male sub-genital plate; F, Male genitalia; G, Female ovipositor upturned, sabre shaped; apexsharp with teeth on ventre. 